\title{
TITLE:
}

\section{Anomaly, impulsivity, and addiction}

$\operatorname{AUTHOR}(\mathrm{S})$ :

Ida, Takanori

\section{CITATION:}

Ida, Takanori. Anomaly, impulsivity, and addiction. Journal of SocioEconomics 2010, 39(2): 194-203

\section{ISSUE DATE:}

2010-04

URL:

http://hdl.handle.net/2433/113883

\section{RIGHT:}

(C) 2010 Elsevier B.V.; This is not the published version. Please cite only the published version.; この論文は出版社版でありません。引用の際に は出版社版をご確認ご利用ください。 


\title{
Anomaly, Impulsivity, and Addiction
}

\section{Takanori Ida ${ }^{+}$}

\begin{abstract}
There are two behavioral approaches to addiction: rational and irrational. The rational approach assumes that addicts have higher time preference rates and lower risk aversion coefficients-parameters that are interpreted as impulsive preferences. On the other hand, the irrational approach argues that addiction is a consequence of anomalies such as non-expected utility and hyperbolically discounted utility. This paper integrates these two approaches and concludes that anomaly and impulsivity complementarily account for addiction.
\end{abstract}

Keywords anomaly, time preference, risk aversion, smoking, gambling JEL classifications D81, D91, I12

\footnotetext{
+ Corresponding author: Takanori Ida, Graduate School of Economics, Kyoto University, Yoshida, Sakyo, Kyoto 606-8501, Japan; Tel. \& Fax: +81-75-753-3477; E-mail: ida@econ.kyoto-u.ac.jp
} 


\section{Introduction}

Why do people suffer from such addictions as smoking and gambling? We analyze this problem with the help of the following two models ${ }^{1}$. The first is the rational addiction model advocated by Becker and Murphy (1988), where a consumer is assumed to think that an addictive product such as cigarettes increases her current satisfaction but decreases her future utility by damaging her health, and then determine the optimum consumption levels. The rational addiction model is compatible with traditional economic models such as the discounted and expected utility schemes. Ida and Goto (2009 in press) verified empirically that impulsive people-those with higher time preference rates and lower risk aversion coefficients-were more likely to be addicted to smoking. We call this the weak rationality approach to addiction.

The second is the irrational addiction model, such as the one incorporated in the study by Gruber and Koszegi (2001), where the exponentially discounted and expected utility hypotheses are systematically violated; individuals neither recognize the true difficulty of quitting nor search for self-control devices to help them quit. Gruber and Koszegi developed a new model of addictive behavior that incorporated anomalies such as time-inconsistency ${ }^{2}$, and also included strikingly different normative implications, since government policy should consider not only the externalities that smokers impose on others but also the internalities imposed by smokers on themselves. We call this the irrationality (or bounded rationality) approach.

Are the two approaches related? Are they complementary or substitutes, if related? These questions will be investigated in this paper. It is also important to verify whether an addict is both impatient and time-inconsistent; and whether a risk-seeker is likely to violate the expected utility hypothesis. Very few studies, however, have been conducted in this vein. An exception is Blondel et al. (2007), who compared the behavior of drug addicts with that of a control group and discovered that the decisions of the drug users, over time and under risk, were not less consistent with standard decision-making theories. Furthermore, they found no differences in the estimated discount rates between

\footnotetext{
${ }^{1}$ Tomer (2001) also discussed addiction from a socio-economic perspective. We will come back to the socio-economic model, based on our estimation results.

${ }^{2}$ Wong (2008) found that time-inconsistent behavior is associated with the inferior class performance of university students.
} 
the drug users and the control group, but the former did appear to be more risk seeking. These conclusions are interesting, although the size of the sample was only 34 . Expanding on the work of Blondel et al. (2007), we draw a large population to examine the relation between the irrationality (anomaly) and the weak rationality (impulsivity) approaches.

This paper establishes three hypotheses. First, we investigate whether anomalies such as non-discounted and non-expected utilities are associated with higher time preference rates or higher risk aversion coefficients. We conclude that discounted utility anomalies can be explained by the immediacy effect, resulting in higher time preference rates; expected utility anomalies can be interpreted as outcomes of the certainty effect, resulting in higher risk aversion coefficients.

Second, we investigate whether smokers who exhibit discounted and expected utility anomalies have higher time preference rates and lower risk aversion coefficients than non-smokers who show evidence of the same anomalies. We obtain the expected results. Ida and Goto (2009 in press) reported that time preference rates were higher and risk aversion coefficients were lower for smokers. This result holds when the discounted and expected utility anomalies are observed. We thus conclude that anomaly (i.e., time inconsistency) and impulsivity (i.e., myopia) are complementary rather than alternating.

Third, we apply our analysis to such forms of gambling as pachinko (a type of Japanese pinball) in order to examine instances of process dependence, as opposed to the substance dependence inspected earlier. We obtain results similar to those for smoking while measuring the time preference rates of pachinko players. We thus conclude that the complementarities between anomaly and impulsivity apply widely for addictive behaviors, although we see different results in the case of the risk aversion coefficients. This is probably because the discounted utility anomaly is associated with the immediacy effect (higher time preference rates), while the expected utility anomaly is related to the certainty effect (lower risk aversion coefficients).

This paper is organized as follows. Section 2 explains the discounted and expected utility anomalies, and Section 3 presents our adopted anomaly survey. Section 4 explains a method that simultaneously measures time preference rates and risk aversion coefficients. Section 5 displays the estimation results. Section 6 illustrates the relationship between anomaly and impulsivity for all samples. Sections 7 and 8 discuss the relationships between smokers and pachinko players. Section 9 elaborates on the 
socio-economic type argument for irrational addiction on the basis of the estimation results. Section 10 outlines our conclusions.

\section{Expected and Discounted Utility Anomalies}

\subsection{The Discounted Utility Anomaly}

First, we explain the discounted utility anomaly. The standard theory of decision-making over time is the exponentially discounted utility model advocated by Samuelson $(1937)^{3}$. Its key assumption is a stationarity axiom, which means that if and only if the utility of JPY 100,000 at present is indifferent to the utility of JPY 150,000 in one year, then the utility of JPY 100,000 in ten years is indifferent to the utility of JPY 150,000 in eleven years.

Given that $X$ and $Y$ denote payoffs $(X<Y)$ and $t$ and $s$ denote time delay $(t<s)$, stationarity is more formally defined as follows:

$$
(X, t) \geq(Y, s) \Leftrightarrow(X, t+\varepsilon) \geq(Y, s+\varepsilon)
$$

Note that $\varepsilon$ is a positive constant.

At this point, the discounted utility model demonstrates $U(X) /(1+r)^{t} \geq U(Y) /(1+$ $r)^{s}$ for $t$ and $s^{4}$. However, the discounted utility anomaly of a present-smaller reward being excessively preferred to a delayed-larger reward indicates the following inconsistent preference orders:

$$
(X, t) \geq(Y, s) \Leftrightarrow(X, t+\varepsilon) \leq(Y, s+\varepsilon) .
$$

This anomaly is called time inconsistency (Strotz 1956) ${ }^{5}$, which is interestingly

\footnotetext{
${ }^{3}$ The exponentially discounted utility model was axiomatically defined by Koopmans (1960) and Fishburn and Rubinstein (1982).

${ }^{4}$ For continuous time, the exponentially discounted utility model is represented by $\exp (-r t) U(X) \geq \exp (-r s) U(Y)$.

${ }^{5} \mathrm{~A}$ model considers a decreasing discount rate as hyperbolically discounting, which is represented by $U(X) /(1+t)^{r}$.
} 
observed even for animals, including pigeons (Ainslie 1975).

We asked respondents two questions in order to investigate the discounted utility anomaly:

Question 1

Alternative 1: Receive JPY 100,000 immediately.

Alternative 2: Receive JPY 150,000 in $X$ years.

What $X$ makes the two alternatives indifferent?

Question 2

Alternative 1: Receive JPY 100,000 in one year.

Alternative 2: Receive JPY 150,000 in Yyears.

What $Y$ makes the two alternatives indifferent?

Note that given US\$1 = JPY 110, JPY 100,000 equals US\$909, while JPY 150,000 is US\$1,364.

Based on the exponentially discounted utility model, when the utility of JPY 100,000 at present equals the utility of JPY 150,000 in $X$ years, we obtain the following equation:

$$
\text { Utility of JPY 100,000 = Utility of JPY 150,000/(1 + r })^{X}
$$

Note that $r$ denotes the annual time preference rate.

On the other hand, when the utility of JPY 100,000 in one year equals the utility of JPY 150,000 in $Y$ years, we obtain the following equation:

$$
\text { Utility of JPY 100,000 /(1+s) = Utility of JPY 150,000/(1+s) }
$$

If the time preference rate is constant $(r=s)$, as the exponentially discounted utility model assumes, then $X=Y-1$ holds. However, the discounted utility anomaly $X /(Y-1)$ $<1$ is frequently observed, so the time preference rate decreases for time delay $(r>s)$. A main reason for this is the immediacy effect in which people tend to lay more 
emphasis on an immediate reward as opposed to a delayed one (Fredrick et al. 2000). In Question 1, since Alternative 1 includes an immediate reward, Alternative 2 requires that $X$ be a relatively small figure (for example, one year). On the other hand, in Question 2, since Alternative 1 includes a one-year-delayed reward, Alternative 2 requires that $Y$ be a large figure (for example, three years). Thus, it follows that $X /(Y-$ 1) $=0.5$.

\subsection{Expected Utility Anomaly}

Next we explain the expected utility anomaly. The standard theory of decision-making under risk is the expected utility model advocated by Von Neumann and Morgenstern (1953). The key assumption of this theory is the independence axiom, which means that if lottery $X$ is preferred to lottery $Y$, mixing lotteries $X$ and $Y$ by third irrelevant lotteries $W$ and $Z$ with a common probability 1-P, preserves the preference orders:

$$
(X, P ; Z, 1-P)>(Y, P ; Z, 1-P) \Leftrightarrow(X, P ; W, 1-P)>(Y, P ; W, 1-P) .
$$

We asked respondents two questions to investigate the expected utility anomaly:

\section{Question 1}

Alternative 1: Receive a guaranteed JPY 100,000.

Alternative 2: Receive JPY 200,000 by X\%.

What $X$ makes the two alternatives indifferent?

Question 2

Alternative 1: Receive JPY 100,000 by 50\%.

Alternative 2: Receive JPY 200,000 by Y\%.

What $Y$ makes the two alternatives indifferent?

Note that given US\$1 = JPY 110, JPY 100,000 equals US\$909, while JPY 200,000 is US $\$ 1,818$. 
Based on the expected utility model, when the utility of JPY 100,000 by 100\% equals the utility of JPY 150,000 by $X$ \%, we obtain the following equation:

$$
\text { Utility of JPY 100,000 = X/100 } \times \text { Utility of JPY 150,000. }
$$

Based on the expected utility model, the preference between Alternatives 1 and 2 is preserved when dividing them by a common ratio. For example, when the utility of JPY 100,000 by $50 \%$ equals the utility of JPY 200,000 by Y\%, we obtain the relationship $X$ $=2 Y$. However, the expected utility anomaly, $2 Y / X<1$, is frequently observed. This is called the common ratio effect or the violation of the independence axiom (Allais 1953). A main reason for this is the certainty effect, whereby people markedly prefer an assured reward in comparison to a risky reward (Starmer 2000). In Question 1, since Alternative 1 is a certain reward, Alternative 2 requires that $X$ be a relatively large value (for example, 0.8). On the other hand, in Question 2, since Alternative 1 includes a risk (with probability 0.5), Alternative 2 requires that $Y$ be a small value (for example, 0.3). Thus, it follows that $2 Y / X=0.75$.

\section{The Results of Anomalies}

This section explains the results of the expected and discounted utility anomalies. In July 2008, we surveyed around 500 Japanese adults registered with a consumer monitoring investigative company. 253 were smokers, and 241 were non-smokers. Looking into the demographics, the male ratio was $56.3 \%$, the average age was 39.3 , the smoking rate was $51.2 \%$, the drinking rate was $82.8 \%$, the pachinko-playing rate was $23.9 \%$, and the horse-race betting rate was $24.5 \%$. The basic statistics are summarized in Table 1. The respondents were classified, with respect to risk preferences, into expected $(2 Y / X=1)$ and non-expected utility types $(2 Y / X<1)$, which are indicated in the rows; and, with respect to time preferences, into the exponentially discounted $(X /(Y$ $-1)=1)$ and non-discounted utility types $(X /(Y-1)<1)$, as shown in the columns.

$<$ Table 1>

Looking at (a), which is the data from all samples, the incidence rate of the 
discounted utility anomaly is $32.6 \%$, while that of the expected utility anomaly is $42.5 \%$. These are similar (though slightly higher) to the values (21.4\% 32.4\%) reported by Blondel et al. (2007). Note that the incidence rate of homo economicus—satisfying both the discounted and expected utility hypotheses—is $41.1 \%$. On the other hand, the rate of incidence of non-homo economicus_-violating both the discounted and expected utility hypotheses-is $16.2 \%$.

Next, we divided the sample into two categories: (b) smokers and (c) non-smokers. The irrational addiction model assumes that addiction is the result of an anomaly. Therefore, the ratio of anomaly is expected to be higher among smokers. Do the results, then, uphold the assumption? The ratios of the expected utility anomaly are $44.7 \%$ for smokers and $40.2 \%$ for non-smokers. In addition, the ratios of the discounted utility anomaly are $35.2 \%$ for smokers and $29.9 \%$ for non-smokers. Although the results are observed to be along expected lines, we cannot conclude that the two categories (smokers and non-smokers) are statistically very different, which is again consistent with Blondel et al. (2007). Viewed from another angle, the ratios of homo economicus-satisfying both the discounted and expected utility hypotheses-are $37.2 \%$ for smokers and $45.2 \%$ for non-smokers. Although these ratios are statistically notably different, the significance level is not high (the $\mathrm{P}$ value is 0.07). We may, therefore, conclude, but only marginally, that smokers tend to be irrational.

Finally, we divided the sample into two further categories: (d) pachinko and (e) non-pachinko. Pachinko has a different aspect to smoking, since the former is a type of process dependence, very distinct from the substance dependence on nicotine. The ratios of the expected utility anomaly are $44.1 \%$ for pachinko players and $42.0 \%$ for pachinko non-players. Further, the ratios of the discounted utility anomaly are 33.9\% for pachinko and $32.2 \%$ for non-pachinko. Since the differences are not statistically significant ${ }^{6}$, we may conclude that those who play pachinko are not necessarily irrational.

The inveterate anomalies raise a question. Do anomalies deny the discounted and expected utility theories? Although the discounted and expected utility anomalies violate the stationarity axiom and the independence axiom necessary for these theories

\footnotetext{
${ }^{6}$ The same thing applies for the differences between those who smoke and play pachinko and those who neither smoke nor play pachinko.
} 
to hold, we should not forget that we have so far dealt with the idiosyncratic cases such as the immediacy and certainty effects inducing anomalies. We consider at this point that measuring economic psychological parameters for time and risk preferences is still useful even if these anomalies occur ${ }^{7}$.

\title{
4. Conjoint Analysis of Time Preference and Risk Aversion
}

In this section, we explain conjoint analysis-a stated preference method that we carried out on 494 valid respondents to simultaneously measure time and risk preferences ${ }^{8}$. Conjoint analysis assumes that a service is a profile composed of attributes. If we include too many attributes and levels, respondents have difficulty answering the questions. On the other hand, if we include too few, the description of the alternatives becomes inadequate. After conducting several pretests, we determined the alternatives, attributes, and levels as follows:

\section{Alternative 1}

Reward, probability, and delay are fixed across profiles.

Reward: JPY100,000 (US\$909), Winning probability: 100\%, Time delay: None.

\author{
Alternative 2 \\ Reward, probability, and delay vary across profiles. \\ Reward is either JPY150,000 (US\$1,364), 200,000 (US\$1,818), 250,000 \\ (US\$2,273), or 300,000 (US\$2,727). \\ The winning probability is $40,60,80$, or $90 \%$. \\ The time delay is 1 month, 6 months, 1 year, or 5 years.
}

Since the number of profiles becomes unmanageable if we consider all possible

\footnotetext{
${ }^{7}$ Some models explaining anomalies may be compatible with the standard theories by a simple transformation of variables. For example, if psychological time is set as a logarithm of physical time, an exponential discounted model with respect to physical time can be transformed into a hyperbolic discounted model for psychological time (Takahashi 2005).

${ }^{8}$ Andersen et al. (2008) discussed that allowing for risk aversion makes a significant difference to the elicited discount rates.
} 
combinations, we avoided this problem by adopting an orthogonal planning method. Figure 1 depicts a representative questionnaire. We asked eight questions per respondent.

$<$ Figure $1>$

Next, we explain the discounted and expected utility models that form the basis for estimating the time preference rates and the risk aversion coefficients. Let the utility of alternative $i$ be $V_{i}$ (reward $\mathrm{r}_{\mathrm{i}}$, probability, timedelay $\mathrm{y}_{\mathrm{i}}$ ). The exponentially discounted utility model and the (linear in probability) expected utility model are used to derive the functional form of $V_{i}$, as follows:

Discounted utility: $\exp \left(-T I M E *\right.$ timedelay $\left._{\mathrm{i}}\right) *$ utility $\left(\right.$ reward $\left._{\mathrm{i}}\right)$,

where parameter TIME denotes the rate of time preference.

Expected utility ${ }^{9}$ : probability $_{\mathrm{i}}{ }^{*}$ utility $\left(\operatorname{reward}_{\mathrm{i}}\right)$.

Accordingly, rewriting $V_{i}$, we obtain

$V_{i}\left(\right.$ reward $_{\mathrm{i}}$, probability $_{\mathrm{i}}$, timedelay $\left.{ }_{\mathrm{i}}\right)$

$=\exp \left(-T I M E *\right.$ timedelay $\left._{\mathrm{i}}\right) *$ probability $_{\mathrm{i}} *$ utility $\left(\right.$ reward $\left._{\mathrm{i}}\right)$.

At this point, we simply specify the functional form of utility as the RISK-th power of reward. Such a utility function is called the constant relatively risk-averse form, where the coefficient of the relative risk aversion is denoted by 1-RISK. Taking the logarithms of both sides, we obtain

$$
\begin{aligned}
& \text { ln } V_{i}\left(\text { reward }_{\mathrm{i}} \text {, probability } \mathrm{y}_{\mathrm{i}} \text {, timedelay }{ }_{\mathrm{i}}\right) \\
& =- \text { TIME }^{*} \text { timedelay }_{\mathrm{i}}+\ln \text { probability }_{\mathrm{i}}+\text { RISK }^{*} \ln \text { reward }_{\mathrm{i}} \text {. }
\end{aligned}
$$

\footnotetext{
${ }^{9}$ If we consider index $s$ the state of nature, $s=1, \ldots, S$, the expected utility, is written as $\Sigma_{s}=1, \ldots, s$ probability $*$ utility $\left(\right.$ reward $\left._{\mathrm{s}}\right)$. Note that here we simply assume that one alternative has only one state of nature other than the state of zero reward.
} 
Two points should be noted here: First, a greater level of impatience implies a larger TIME; second, since a risk-averse attitude is denoted by $1-R I S K \in[0,1]$, a greater level of risk-aversion implies a larger value of 1-RISK.

Finally, we explain the estimation models. Conditional logit (CL) models, which assume independent and identical distribution (IID) of random terms, have been widely used in past studies. However, the property of independence from the irrelevant alternatives (IIA), derived from the IID assumption of the CL model, is too strict to allow flexible substitution patterns. The most appropriate scheme, then, is a mixed logit (ML) model that accommodates differences in the variance of random components (or unobserved heterogeneity). These models are flexible enough to overcome the limitations of CL models by allowing random taste variation, unrestricted substitution patterns, and the correlation of random terms over time (McFadden and Train 2000). See the APPENDIX for details of ML models.

In what follows, we assume that the preference parameters regarding time and risk follow normal distribution.

TIME (rate of time preference)

RISK (coefficient of relative risk aversion represented by 1-RISK).

We can demonstrate variety in the parameters at the individual level, using the maximum simulated likelihood (MSL) method for estimation, by setting 100 Halton draws $^{10}$. Furthermore, with respondents answering eight questions in the conjoint analysis, the resultant data form a panel, allowing us the option to apply standard random effect estimation. We can now calculate the estimator of the conditional mean of the random parameters at the individual level.

\section{The Estimation Results of Conjoint Analysis}

In this section, the rate of time preference and the coefficient of relative risk aversion

\footnotetext{
${ }^{10}$ The adoption of the Halton sequence draw is an important issue to be examined (Halton 1960). Bhat (2001) found that 100 Halton sequence draws are more efficient than 1,000 random draws for simulating an ML model.
} 
are measured simultaneously on the basis of the estimation results. Having assumed that the random parameters follow normal distribution, their means and standard deviations are reported. The estimation results are displayed in Table 2, separately, for the "both discounted \& expected utility" samples (203), and for the "both non-discounted \& non-expected utility" samples (80). The means and standard deviations of both TIME (the time preference parameter) and RISK (the risk preference parameter) are statistically significant. The time preference rate is $5.05 \%$ for the "both discounted \& expected utility" type and 8.14\% for the "both non-discounted \& non-expected utility" type. The risk aversion coefficient is $-7.54 \%{ }^{11}$ for the "both discounted \& expected utility" type, and $19.69 \%$ for the "both non-discounted \& non-expected utility" type. Since the volume of estimation results is enormous, we omit other estimations and display only the time preference rates and risk aversion coefficients below.

$<$ Table 2>

Based on the estimation results, we measured the time preference rates and the risk aversion coefficients for various cases. The results, covering all of the sample data, are indicated in Table 3. Table 3(a) displays the means and standard errors of the time preference rates for the discounted (333 samples) and non-discounted utility types (161 samples). Table 3(b) displays the means and standard errors of the risk aversion coefficients for the expected (284 samples) and non-expected utility types (210 samples). Table 3(c) displays the means and standard errors of the time preference rates and risk aversion coefficients for the "both discounted \& expected utility" type (203 samples) and the "both non-discounted \& non-expected utility" type (80 samples).

$<$ Table 3>

Similarly, the results for the smokers and non-smokers are indicated in Tables 4 and 5. Furthermore, the results for the pachinko players and non-pachinko players are indicated in Tables 6 and 7.

\footnotetext{
${ }^{11}$ Therefore, the "both discounted \& expected utility" type is defined as a risk-seeking type.
} 
$<$ Table 4>

$<$ Table 5>

$<$ Table 6>

$<$ Table $7>$

\section{Anomaly and Impulsivity for All Data}

In this section, we investigate the relationship between anomaly and impulsivity for all the data. We begin by building certain hypotheses and verifying them. The discounted utility anomaly can be explained by the immediacy effect, since the serious consideration of immediacy represents a preference ruled by impatience and therefore implies a higher time preference rate. Likewise, the expected utility anomaly can be explained by the certainty effect, since the serious consideration of certainty represents a preference for risk aversion and therefore implies a higher risk aversion coefficient ${ }^{12}$.

Hypothesis 1.1: Time preference rates will be higher for the non-discounted utility type than for the discounted utility type.

Result 1.1: Yes. The time preference rates are 5.14\% for the discounted utility type and $7.44 \%$ for the non-discounted utility type (see Table 3(a)). Based on the test of difference in the mean values, the $t$-value is 23.73; the time preference rates are significantly different between the discounted and the non-discounted utility types.

Hypothesis 1.2: Risk aversion coefficients will be higher for the non-expected utility type than for the expected utility type.

Result 1.2: Yes. The risk aversion coefficients are $-0.89 \%$ for the expected utility type and $14.45 \%$ for the non-expected utility type (see Table 3(b)). Since the $t$-value is 16.86 , the risk aversion coefficients are significantly different between the expected and the non-expected utility types.

\footnotetext{
${ }^{12}$ Risk anomaly can perhaps be attributed to the certainty effect and be interpreted as loss aversion. It still remains unclear why risk preference appears to be more complicated than time preference.
} 
As expected, it follows that the discounted utility anomaly is associated with impatience (and higher time preference rates), while the expected utility anomaly is related to the preference for risk aversion (and higher risk aversion coefficients). The former result with respect to time preference is consistent with the previous literature, thereby, indicating that smokers tend to discount both hyperbolically and myopically (Kirby et al. 1999).

On the other hand, the interpretation of the latter result with respect to risk preference is difficult, because the expected utility anomaly is associated with risk-averse preferences and is not necessarily impulsive. This may account for the well-known fact that, contrary to expectations, smokers do not always discount risk more heavily than non-smokers. This phenomenon ought to be examined later in detail, having been noted by various previous studies. ${ }^{13}$

Let us here compare homo economicus (consistent with both the discounted and expected utility hypotheses) and non-homo economicus (exhibiting both the discounted and expected anomalies). Observations similar to Results 1.1 and 1.2 are assured.

Hypothesis 1.3: Higher time preference rates and higher risk aversion coefficients will be found for the "both non-discounted \& non-expected utility" type than for the "discounted \& expected utility" type.

Result 1.3: Yes. The time preference rate is $8.14 \%$ and the risk aversion coefficient is $19.69 \%$ for the "both non-discounted \& non-expected utility" type, while for the "both discounted \& expected utility" type, the time preference rate is $5.05 \%$ and the risk aversion coefficient is $-7.54 \%$ (see Table $3(\mathrm{c})$ ). Since the $t$-values are 14.69 for the time preference rates and 13.28 for the risk aversion coefficients, it may be asserted that the time and risk preferences are significantly different between the two types.

Finally, we may conclude that the discounted utility anomaly is associated with higher time preference rates, and the expected utility anomaly is connected with higher risk aversion coefficients.

\footnotetext{
${ }^{13}$ Examples include Mitchell (1999), Reynolds et al. (2003), and Ohmura et al. (2005).
} 


\section{Anomaly and Impulsivity for Smokers}

In this section, we investigate the relationship between anomaly and impulsivity for smokers and non-smokers. Table 4 displays the means and standard errors of the time preference rates and the risk aversion coefficients for smokers: the time preference rates for the discounted utility type (164 samples) and the non-discounted utility type (89 samples); the risk aversion coefficients for the expected utility type (140 samples) and the non-expected utility type (113 samples); the "both discounted \& expected utility" type (94 samples) and the "both non-discounted \& non-expected utility" type (43 samples). Table 5 also displays the means and standard errors of the time preference rates and the risk aversion coefficients for non-smokers. It is easily verified that Hypotheses 1.1, 1.2, and 1.3 can be reproduced.

Following Ida and Goto (2009 in press), we simultaneously measured the time preference rates and the risk aversion coefficients. We, therefore, expect identical conclusions to those obtained in Ida and Goto, that smokers are impatient and risk-seeking (see also Mitchell 1999, Bickel et al. 1999, Odum et al. 2002, Baker et al. 2003, Reynolds et al. 2004, Ohmura et al. 2005). We are here concerned with the following differences in the time preference rates: first, between the discounted utility smokers and the same type non-smokers; and second, between the non-discounted utility smokers and the same type non-smokers. Similarly, we examine the differences in the risk aversion coefficients: first, between the expected utility smokers and the same type non-smokers, and second, between the non-expected utility smokers and the same type non-smokers.

Hypothesis 2.1: Time preference rates will be higher for discounted utility smokers than for the same type non-smokers.

Result 2.1: Yes. The time preference rates are 5.81\% for the discounted utility smokers and 5.15\% for the same type non-smokers (see Tables 4(a) and 5(a)). Since the $t$-value is 7.06 , the time preference rates are significantly different between the smokers and non-smokers within the discounted utility type.

Hypothesis 2.2: The time preference rates will be higher for non-discounted utility 
smokers than for the same type non-smokers.

Result 2.2: Yes. The time preference rates are $9.03 \%$ for the non-discounted utility smokers and 5.67\% for the same type non-smokers (see Tables 4(a) and 5(a)). Since the $t$-value is 12.05 , the time preference rates are significantly different between the non-discounted utility smokers and the non-smokers of the same type.

These conclusions for time preference rates are as expected. Note that the difference between the non-discounted utility smokers and non-smokers (Result 2.2) is larger than that between the discounted utility smokers and non-smokers (Result 2.1).

Hypothesis 2.3: The risk aversion coefficients will be lower for the expected utility smokers than for the same type non-smokers.

Result 2.3: No. The risk aversion coefficients are $1.21 \%$ for the expected utility smokers and $-1.21 \%$ for the same type non-smokers (see Tables $4(b)$ and 5(b)). Since the $t$-value is 1.53 , the risk aversion coefficients are not significantly different between the expected utility smokers and the non-smokers of the same type.

Hypothesis 2.4: Risk aversion coefficients will be lower for non-expected utility smokers than for the same type non-smokers.

Result 2.4: Yes. The risk aversion coefficients are $8.91 \%$ for the non-expected utility smokers and $15.31 \%$ for the same type non-smokers (see Tables 4(b) and $5(b))$. Since the $t$-value is 3.29 , the risk aversion coefficients are significantly different between the non-expected utility smokers and the same type non-smokers.

These results for the risk aversion coefficients are only partly as expected; smokers are more risk-averse than non-smokers only when the expected utility anomaly occurs (Result 2.4).

To check the robustness of these results, let us compare homo economicus (consistent with both discounted \& expected utility hypotheses) and non-homo economicus (exhibiting both discounted \& expected anomalies). 
Hypothesis 2.5: Hypotheses 2.1-2.4 will hold when comparing smokers and non-smokers.

Result 2.5: No (2.1), Yes (2.2-2.4). Only Hypothesis 2.1 does not stand verified; the time preference rates are 5.03\% for the "both discounted \& expected utility" smokers and 5.11\% for the same type non-smokers (see Tables 4(c) and 5(c)). Since the $t$-value is 0.5368 , the time preferences are not significantly different between the "both discounted \& expected utility" smokers and non-smokers. On the other hand, Hypotheses 2.2-2.4 are verified. Their t-values are 3.53, 7.19, and 3.55 .

To summarize these results, when the discounted and/or expected utility anomalies occur, the time preference rates are higher and the risk aversion coefficients are lower for smokers than for non-smokers ${ }^{14}$. As such, the grounds for addiction are simultaneously provided by the weak rationality and the irrationality approaches. An important question here is whether impulsivity and anomaly work complementarily or as substitutes of each other. Our findings indicate that the two approaches are complementary, which is consistent with Gruber and Koszegi (2001).

\section{Anomaly and Impulsivity for Pachinko}

Section 7 dealt with smoking as an addiction and discussed the possible complementarities between impulsivity and anomaly for smokers. While smoking is a form of substance dependence that physiologically influences people's preferences, it has been pointed out that preferences are affected not only by substance dependence but also by process dependence as well. It has also been reported that cross addiction exists among such activities as smoking, drinking, and gambling (Pierani and Tiezzi 2008; Ida and Goto 2007). As such, this section addresses pachinko, a type of Japanese pinball, as a process addiction. If the results obtained in the previous section hold for the pachinko process dependence, we may judge that our results apply widely across different addiction forms ${ }^{15}$.

\footnotetext{
${ }^{14}$ Note, on the other hand, that when the discounted and/or expected utility anomalies do not operate, smokers are not necessarily impulsive.

${ }^{15} \mathrm{An}$ interesting model of gambling behavior was proposed by Nyman et al., addressing
} 
Hypothesis 3.1: Time preference rates will be higher for discounted utility pachinko players than for the same type pachinko non-players.

Result 3.1: Yes. The time preference rates are $7.45 \%$ for discounted utility pachinko players and 5.08\% for the same type pachinko non-players (see Tables 6(a) and 7(a)). Since the $t$-value is 12.39 , the time preference rates are significantly different between the players and non-players within the discounted utility type.

Hypothesis 3.2: Time preference rates will be higher for non-discounted utility pachinko players than for the same type pachinko non-players.

Result 3.2: Yes. The time preference rates are 9.76\% for non-discounted utility pachinko players and $6.14 \%$ for the same type pachinko non-players (see Tables 6(a) and 7(a)). Since the $t$-value is 7.18 , the time preference rates are significantly different between the non-discounted utility pachinko players and non-players.

First, we observed that the results obtained for smokers with respect to the time preference rates hold for pachinko players as well. Next, we investigate the risk aversion coefficients.

Hypothesis 3.3: Risk aversion coefficients will be lower for expected utility pachinko players than for the same type pachinko non-players.

Result 3.3: Yes. The risk aversion coefficients are 6.01\% for expected utility pachinko players and $0.10 \%$ for the same type pachinko non-players (see Tables 6(b) and 7(b)). Since the $t$-value is 2.19, the risk aversion coefficients are significantly different between the expected utility pachinko players and non-players.

Hypothesis 3.4: Risk aversion coefficients will be lower for non-expected utility pachinko players than for the same type non-players.

Result 3.4: No. The risk aversion coefficients are $10.21 \%$ for non-expected utility

the ability to obtain "something for nothing” (2008). Also, the relationship between gambling and bankruptcy was investigated by Boardman and Perry (2007). 
pachinko players and $12.20 \%$ for the same type non-players (see Tables 7(b) and 7(b)). Since the $t$-value is 0.63 , the risk aversion coefficients are not significantly different between the non-expected utility pachinko players and non-players.

Contrary to Result 2.4 for smoking, Result 3.4, concerning the risk aversion coefficients of the non-expected utility pachinko players and non-players, did not support the hypothesis. Although the exact background of this result remains indistinct, it is at least certain that, overall, the complementarities between impulsivity and anomaly are less obvious for risk preference than they are for time preference.

To check the robustness of these results, we may again compare homo economicus (consistent with both discounted and expected utility hypotheses) and non-homo economicus (exhibiting both discounted and expected anomalies).

Hypothesis 3.5: Hypotheses 3.1-3.4 will hold when comparing pachinko players and non-players.

Result 3.5: Yes. Hypotheses 3.1-3.4 are verified at least at the $10 \%$ significance level (see Tables 6(c) and 7(c)). Their $t$-values are 6.71, 7.69, 9.71, and 1.76.

The results obtained for pachinko (Result 3.5) are more robust than those for smoking (Result 2.5), and all the expected results are reproduced for pachinko. On the whole, the time preference rates were higher among the non-discounted utility addicts, for such activities as smoking and gambling, than the same type non-addicts.

\section{Discussions}

We have so far seen that addiction can be explained both on the grounds of impulsivity (higher time preference and lower risk aversion) and anomaly (non-discounted and non-expected utilities). The question then arises as to why impulsivity and anomaly complementarily account for addiction. This section will discuss certain insights into addiction that were gained using the socio-economic model advocated by Tomer (2001).

The socio-economic approach assumes that people who become addicts suffer from significant imbalance, which impairs their ability to obtain real satisfaction from life's 
activities. When a person's degree of imbalance reaches a certain threshold and the individual finds an addictive good that restores a sense of balance, addiction is likely to be formed.

Five external and internal influences determine an individual's degree of imbalance: 1) the individual's personal capital, 2) the individual's social capital, 3) the individual's consumption capital, 4) the societal and community influences on the individual, and 5) the stressfulness of the individual's current life situation. Among the five factors above, the individual's personal capital endowment is the most important factor; the others serve to moderate or exacerbate the imbalance.

Personal capital is defined as the human capacity that derives itself from an individual's basic personal qualities. An important component of personal capital is emotional intelligence, which determines one's ability to motivate him/herself, to persist in the face of frustrations, to control impulses, to delay gratification, to regulate one's mood, and so on.

At this point, we can integrate Tomer's socio-economic model and our economic-psychological model. The economic-psychological parameters of impulsivity and anomaly reflect the degrees of imbalance. When one fails to control oneself, the time preference rate is higher and the risk aversion coefficient is lower; at the same time, one tends to demonstrate non-discounted and non-expected utility behavior.

In sum, an individual with a significant imbalance is likely to manifest defective mental processing (imbalance) that leads to a biased perception of the expected benefits and costs of an addictive behavior. The degree of imbalance can be represented by impulsivity and anomaly. When the bias caused by impulsivity and anomaly is strong, the individual is oriented to perceiving the use of an addictive good favorably. Figure 2 summarizes the schema.

\section{$<$ Figure 2>}

Finally, we discuss briefly the self-control issues. When discussing these, we should differentiate meta-preferences from actual preferences (Tomer 1996). While one's actual preferences are innately determined, they are also influenced by the degree to which one has developed the capacity to appreciate goods. On the other hand, one's meta-preferences are his/her choices of actual preferences and reflect the normative 
judgments of a higher order self. Meta-preferences are derived from our wise, rational, and long-term oriented contemplation and are, thus, often in conflict with our actual preferences. If one has a good meta-preference that is strong enough to restrain a bad actual preference, one's socio-economic preferences will become time-patient, risk-averse, and of discounted- and expected-utility types. It is thus natural that ex-addicts who have overcome their past addictive behaviors are the most rational (Ida and Goto 2009).

\section{Conclusion}

Two approaches explain addiction: weak rationality and anomaly. The former assumes that smokers have higher time preference rates and lower risk aversion coefficients - a condition that may also be termed as impulsive preference. On the other hand, the latter approach argues that addiction results from anomalies such as non-discounted or non-expected utility. In this paper, we investigated whether these two approaches were complementary or substitutes. We found that they are complementary and may thus conclude that anomaly is compatible with impulsivity. In addition, the time preference rates were found to be higher for discounted utility addicts than for the same type non-addicts, and the same thing holds true for non-discounted utility addicts and non-addicts. However, the conclusions concerning risk aversion coefficients are less stark between addicts and non-addicts. Ultimately, on the subject of future research, an important premise could be set up by the question: Why is risk preference more complicated than time preference while examining addiction? 


\section{APPENDIX ML Model}

Assuming that parameter $\beta_{n}$ is distributed with density function $f\left(\beta_{n}\right)$ (Train 2003, Louviere et al. 2000), the ML specification allows for repeated choices by each sampled decision maker in such a way that the coefficients vary over people but are constant over choice situations for each person. The logit probability of decision maker $n$ choosing alternative $i$ in choice situation $t$ is expressed as

$$
L_{n i t}\left(\beta_{n}\right)=\prod_{t=1}^{T}\left[\exp \left(V_{n i t}\left(\beta_{n}\right)\right) / \sum_{j=1}^{J} \exp \left(V_{n j t}\left(\beta_{n}\right)\right)\right]
$$

which is the product of normal logit formulas, given parameter $\beta_{n}$, the observable portion of utility function $V_{n i t}$, and alternatives $j=1, \ldots, J$ in choice situations $t=1, \ldots, T$. Therefore, ML choice probability is a weighted average of logit probability $L_{n i t}\left(\beta_{n}\right)$ evaluated at parameter $\beta_{n}$ with density function $f\left(\beta_{n}\right)$, which can be written as

$$
P_{n i t}=\int L_{n i t}\left(\beta_{n}\right) f\left(\beta_{n}\right) d \beta_{n} \text {. }
$$

In the linear-in-parameter form, the utility function can be written as

$$
U_{n i t}=\gamma^{\prime} x_{n i t}+\beta_{n}^{\prime} z_{n i t}+\varepsilon_{n i t},
$$

where $x_{\text {nit }}$ and $z_{\text {nit }}$ denote observable variables, $\gamma$ denotes a fixed parameter vector, $\beta_{n}$ denotes a random parameter vector, and $\varepsilon_{n i t}$ denotes an independently and identically distributed extreme value (IIDEV) term.

Since ML choice probability is not expressed in closed form, simulations need to be performed for the ML model estimation (see Train 2003, p. 148 for details). We can also calculate the estimator of the conditional mean of the random parameters, conditioned on individual specific choice profile $y_{n}$, given as

$$
h\left(\beta \mid y_{n}\right)=\left[P\left(y_{n} \mid \beta\right) f(\beta)\right] / \int P\left(y_{n} \mid \beta\right) f(\beta) d \beta \text {. }
$$

Here, we assume that preference parameters regarding time and risk follow normal distribution:

TIME (rate of time preference)

RISK (coefficient of relative risk aversion represented by 1-RISK).

The random utility that person $n$ obtains from choosing alternative $i$ in choice situation $t$ can be written as follows: 
$U_{n i t}=-\alpha *$ TIME $^{*}$ timedelay $_{n i t}+\alpha * \ln$ probability $_{\text {nit }}+\alpha *$ RISK $^{*} \ln$ reward $_{n i t}+\varepsilon_{n i t}$, where is a scale parameter that is not separately identified from free parameters and is normalized to one (Hensher, Rose, and Green 2005, p. 536) ${ }^{16}$.

16 Louviere, Hensher, and Swait (2000, pp. 142-143) showed that variance is an inverse function of the scale, $\sigma^{2}=\pi^{2} / 6 \alpha^{2}$. Therefore, associated variance $\sigma^{2}$ becomes 1.645. 


\section{References}

Ainslie, G., 1975. Specious Reward: A Behavioral Theory of Impulsiveness and Impulse Control. Psychological Bulletin 82: 463-496.

Allais, M., 1953. Le Comportement de L’homme Rationnel Devant le Risque: Critique des Postulats et Axiomes de L’école Américaine. Econometrica 21: 503-546.

Andersen, S., Harrison, G.W., Lau, M.I., and Rutström, E.E., 2008. Eliciting Risk and Time Preferences . Econometrica 76: 583-618.

Baker, F., Johnson, M.W., and Bickel, W.K., 2003. Delay Discounting in Current and Never-before Cigarette Smokers: Similarities and Differences across Commodity, Sign, and Magnitude. Journal of Abnormal Psychology 112: 382-392.

Becker, G. and Murphy, D. A., 1988. A Theory of Rational Addiction. Journal of Political Economy 96: 675-700.

Bhat, C., 2001. Quasi-random Maximum Simulated Likelihood Estimation of the Mixed Multinomial Logit Model. Transportation Research B 35: 677-693.

Bickel, W.K., Odum, A.L., and Madden, G.J., 1999. Impulsivity and Cigarette Smoking: Delay Discounting in Current Never, and Ex-smokers. Psychopharmacology 146: 447-454.

Blondel, S., Lohéac, Y., and Rinaudo, S., 2007. Rationality and Drug Use: An Experimental Approach. Journal of Health Economics 26: 643-658.

Boardman, B., and Perry, J.J. 2007. Access to Gambling and Declaring Personal Bankruptcy. Journal of Socio-Economics 36: 789-801.

Fishburn, P.C. and Rubinstein, A., 1982. Time Preference. International Economic Review 23: 677-694.

Frederick, S., Lowenstein, G., and O'Donoghue, T., 2002. Time Discounting and Time Preference: A Critical Review. Journal of Economic Literature 40: 351-401.

Gruber, J. and Koszegi, B., 2001. Is Addiction "Rational": Theory and Evidence. Quarterly Journal of Economics, 116: 1261-1303.

Halton, J., 1960. On the Efficiency of Evaluating Certain Quasi-random Sequences of Points in Evaluating Multi-dimensional Integrals. Numerische Mathematik 2: 84-90.

Hensher, D.A., Rose, J.M., and Greene, W.H., 2005. Applied Choice Analysis. Cambridge University Press. 
Ida, T. and Goto, R., 2007. Interdependency among Addictive Behaviors and Time/Risk

Preferences. Graduate School of Economics, Kyoto University, COE21 Discussion Paper No.138.

Ida, T. and Goto, R., 2009. Simultaneous Measurement of Time and Risk Preferences:

Stated Preference Discrete Choice Modeling Analysis Depending on Smoking

Behavior. International Economic Review 50,: 1169-1182.

Kirby, K.N., Petry, N.M., and Bickel, W.K., 1999. Heroin Addicts Have Higher

Discount Rates for Delayed Rewards than Non-drug-using Controls. Journal of Experimental Psychology: General 128, 78-87.

Koopmans, T.C., 1960. Stationary Ordinal Utility and Impatience. Econometrica 28: 287-309.

Louviere, J.J., Hensher, D.A., and Swait, J.D., 2000. Stated Choice Methods, Cambridge University Press.

McFadden, D. and Train, K.E., 2000. Mixed MNL Models of Discrete Choice Models of Discrete Response. Journal of Applied Econometrics 15: 447-470.

Mitchell, S.H., 1999. Measures of Impulsivity in Cigarette Smokers and Non-smokers. Psychopharmacology 146: 455-464.

Neumann, J.V. and Morgenstern, O., 1953. The Theory of Games and Economic Behavior, Princeton University Press.

Nyman, J.A., Welte, J.W., and Dowd, B.E., 2008. Something for Nothing: A Model of Gambling Behavior. Journal of Socio-Economics 37: 2492-2504.

Odum, A.L., Madden, G.J., and Bickel, W.K., 2002. Discounting of Delayed Health Gains and Losses by Current, Never- and Ex-smokers of Cigarettes. Nicotine and Tobacco Research 4: 295-303.

Ohmura, Y., Takahashi, T. and Kitamura, N., 2005. Discounting Delayed and Probabilistic Monetary Gains and Losses by Smokers of Cigarettes. Psychopharmacology (Berl) 182: 508-515.

Pierani, P. and Tiezzi, S., 2008. Addiction and Interaction between Alcohol and Tobacco Consumption. Empirical Economics, forthcoming.

Reynolds, B., Karraker, K., Horn, K., and Richards, J.B., 2003. Delay and Probability

Discounting as Related to Different Stages of Adolescent Smoking and Non-smoking. Behavioural Processes 64: 333-344.

Reynolds, B., Richards, J.B., Horn, K., and Karraker, K., 2004. Delay Discounting and 
Probability Discounting as Related to Cigarette Smoking Status in Adults. Behavioural Processes 65: 35-42.

Samuelson, P., 1937. A Note on Measurement of Utility. Review of Economic Studies 4: $155-161$.

Starmer, C., 2000. Developments in Non-expected Utility Theory: The Hunt for a Descriptive Theory of Choice under Risk. Journal of Economic Literature 38, 332-382.

Strotz, R., 1956. Myopia and Inconsistency in Dynamic Utility Maximization. Review of Economic Studies 23: 165-180.

Takahashi, T., 2005. Loss of Self-control in Intertemporal Choice May Be Attributable to Logarithmic Time-perception. Medical Hypotheses 65: 691-693.

Train, K.E., 2003. Discrete Choice Methods with Simulation, Cambridge University Press.

Tomer, J.F. 1996. Good Habits and Bad Habits: A New Age Socio-Economic Model of Preference Formation. Journal of Socio-Economics 25: 619-638.

Tomer, J.F. 2001. Addictions Are Not Rational: A Socio-economic Model of Addictive Behavior. Journal of Socio-Economics 30: 243-261.

Wong, W-K., 2008. How Much Time-inconsistency Is There and Does It Matter? Evidence on Self-awareness, Size, and Effects. Journal of Economic Behavior \& Organization 68: 645-656. 
Figure 1: Representative questionnaire

\begin{tabular}{|c|c|c|}
\hline & ALTERNATIVE 1 & ALTERNATIVE 2 \\
\hline REWARD & JPY 100,000 & JPY 250,000 \\
\hline TIME DELAY & NOW & 1 MONTH LATER \\
\hline WINNING PROBABILITY & $100 \%$ & $80 \%$ \\
\hline & $\downarrow$ & $\downarrow$ \\
\hline CHOOSE ONE & & \\
\hline
\end{tabular}


Table 1: Expected and Discounted Utilities Anomalies

(a) All samples data

\begin{tabular}{|c|c|c|c|c|}
\cline { 3 - 5 } \multicolumn{2}{c|}{} & Discounted utility & Non-discounted utility & \multirow{2}{*}{ Total } \\
\cline { 2 - 5 } \multicolumn{1}{c|}{} & $\mathrm{X} /(\mathrm{Y}-1)=1$ & $\mathrm{X} /(\mathrm{Y}-1)<1$ & \\
\hline \multirow{3}{*}{$\begin{array}{c}\text { Risk } \\
\text { discounting }\end{array}$} & Expected utility & 203 & 81 & 284 \\
\cline { 2 - 5 } & $2 \mathrm{Y} / \mathrm{X}=1$ & $41.1 \%$ & $16.4 \%$ & $57.5 \%$ \\
\cline { 2 - 5 } & Non-expected utility & 130 & 80 & 210 \\
& $2 \mathrm{Y} / \mathrm{X}<1$ & $26.3 \%$ & $16.2 \%$ & $42.5 \%$ \\
\cline { 2 - 5 } & & 333 & 161 & 494 \\
& Total & $67.4 \%$ & $32.6 \%$ & $100 \%$ \\
\hline
\end{tabular}


(b) Smokers

\begin{tabular}{|c|c|c|c|}
\hline \multirow{3}{*}{ Discounted utility } & \multicolumn{3}{|c|}{ Time discounting } \\
\hline & Discounted utility & Non-discounted utility & \multirow{2}{*}{ Total } \\
\hline & $\mathrm{X} /(\mathrm{Y}-1)=1$ & $\mathrm{X} /(\mathrm{Y}-1)<1$ & \\
\hline Expected utility & 94 & 46 & 140 \\
\hline $2 \mathrm{Y} / \mathrm{X}=1$ & $37.2 \%$ & $18.2 \%$ & $55.3 \%$ \\
\hline Non-expected utility & 70 & 43 & 113 \\
\hline $2 \mathrm{Y} / \mathrm{X}<1$ & $27.7 \%$ & $17.0 \%$ & $44.7 \%$ \\
\hline \multirow{2}{*}{ Total } & 164 & 89 & 253 \\
\hline & $64.8 \%$ & $35.2 \%$ & $100 \%$ \\
\hline
\end{tabular}

(c) Non-smokers

Time discounting

\begin{tabular}{|c|c|c|c|c|}
\cline { 3 - 4 } \multicolumn{2}{c|}{ Discounted utility } & Discounted utility & Non-discounted utility & \multirow{2}{*}{ Total } \\
\cline { 3 - 4 } \multicolumn{1}{c|}{ Risk } & $\mathrm{X} /(\mathrm{Y}-1)=1$ & $\mathrm{X} /(\mathrm{Y}-1)<1$ & \\
\cline { 2 - 5 } discounting & Expected utility & 109 & 35 & 144 \\
& $2 \mathrm{Y} / \mathrm{X}=1$ & $45.2 \%$ & $14.5 \%$ & $59.8 \%$ \\
\cline { 2 - 5 } & Non-expected utility & 60 & 37 & 97 \\
\cline { 2 - 5 } & $2 \mathrm{Y} / \mathrm{X}<1$ & $24.9 \%$ & $15.4 \%$ & $40.2 \%$ \\
\cline { 2 - 5 } & & 169 & 72 & 241 \\
& Total & $70.1 \%$ & $29.9 \%$ & $100 \%$ \\
\hline
\end{tabular}


(d) Pachinko

\begin{tabular}{|c|c|c|c|}
\cline { 2 - 3 } \multicolumn{2}{c|}{} & \multicolumn{3}{c|}{ Time discounting } \\
\cline { 2 - 3 } Discounted utility & Discounted utility & Non-discounted utility & \multirow{2}{*}{ Total } \\
\cline { 2 - 3 } & $\mathrm{X} /(\mathrm{Y}-1)=1$ & $\mathrm{X} /(\mathrm{Y}-1)<1$ & \\
\hline Expected utility & 49 & 17 & 66 \\
$2 \mathrm{Y} / \mathrm{X}=1$ & $41.5 \%$ & $14.4 \%$ & $55.9 \%$ \\
\hline Non-expected utility & 29 & 23 & 52 \\
$2 \mathrm{Y} / \mathrm{X}<1$ & $24.6 \%$ & $19.5 \%$ & $44.1 \%$ \\
\hline Total & 78 & 40 & 118 \\
& $66.1 \%$ & $33.9 \%$ & $100 \%$ \\
\hline
\end{tabular}

(e) Non-pachinko

\begin{tabular}{|c|c|c|c|c|}
\cline { 3 - 4 } \multicolumn{2}{c|}{ Total } & Discounted utility & Non-discounted utility & \multirow{2}{*}{ Total } \\
\cline { 3 - 4 } \multicolumn{1}{c|}{} & $\mathrm{X} /(\mathrm{Y}-1)=1$ & $\mathrm{X} /(\mathrm{Y}-1)<1$ & \\
\hline \multirow{4}{*}{$\begin{array}{c}\text { Risk } \\
\text { discounting }\end{array}$} & Expected utility & 154 & 64 & 218 \\
& $2 \mathrm{Y} / \mathrm{X}=1$ & $41.0 \%$ & $17.0 \%$ & $58.0 \%$ \\
\cline { 2 - 5 } & Non-expected utility & 101 & 57 & 158 \\
& $2 \mathrm{Y} / \mathrm{X}<1$ & $26.9 \%$ & $15.2 \%$ & $42.0 \%$ \\
\cline { 2 - 5 } & & 255 & 121 & 376 \\
& Total & $67.8 \%$ & $32.2 \%$ & $100 \%$ \\
\hline
\end{tabular}


Table 2: Estimation Results of Conjoint Analysis

\begin{tabular}{ccccc} 
& $\begin{array}{c}\text { Discounted \& } \\
\text { expected utility }\end{array}$ & $\begin{array}{c}\text { Non-discounted \& } \\
\text { non-expected utility }\end{array}$ \\
\cline { 2 - 5 } & & & & \\
No. of Samples & $203 * 8$ & & $80 * 8$ & \\
Maximum LL & -866.5 & & -314.3 & \\
Initial LL & -1125.7 & & -443.6 & \\
Pseudo R2 & 0.230 & & 0.292 & \\
\hline & & & & \\
& Coeff./S.E. & & Coeff./S.E. & \\
\cline { 2 - 5 } TIME (MEAN) & 0.0505 & $* * *$ & 0.0814 & $* * *$ \\
& 0.0069 & & 0.0183 & \\
RISK (MEAN) & 1.0754 & $* * *$ & 0.8031 & $* * *$ \\
& 0.1086 & & 0.1702 & \\
TIME (S.D.) & 0.0296 & $* * *$ & 0.0437 & $* * *$ \\
& 0.0079 & & 0.0141 & \\
RISK (S.D.) & 0.7907 & $* * *$ & 0.3762 & $* * *$ \\
& 0.1444 & & 0.3616 & \\
\hline
\end{tabular}

Note: Coefficients in the upper row, standard errors (S.E.) in the lower row, ${ }^{* * *}$ at the $1 \%$ significance level, $* *$ at the $5 \%$ significance level,

*at the $10 \%$ significance level. 
Table 3: Time preference rates and risk aversion coefficients for all sample data

\begin{tabular}{|c|c|c|c|}
\hline (a) & & $\begin{array}{l}\text { Discounted utility } \\
\text { (Sample No.=333) }\end{array}$ & $\begin{array}{l}\text { Non-discounted utility } \\
\text { (Sample No.=161) }\end{array}$ \\
\hline \multirow{2}{*}{ Time preference rates } & Mean & 0.0514 & 0.0744 \\
\hline & Standard error & 0.0061 & 0.0131 \\
\hline (b) & & $\begin{array}{c}\text { Expected utility } \\
\text { (Sample No.=284) }\end{array}$ & $\begin{array}{l}\text { Non-expected utility } \\
(\text { Sample No. }=210)\end{array}$ \\
\hline \multirow{2}{*}{$\begin{array}{l}\text { Risk aversion } \\
\text { coefficients }\end{array}$} & Mean & -0.0089 & 0.1445 \\
\hline & Standard error & 0.0816 & 0.1005 \\
\hline (c) & & $\begin{array}{c}\text { Discounted \& } \\
\text { expected utility } \\
\text { (Sample No.=203) }\end{array}$ & $\begin{array}{l}\text { Non-discounted \& } \\
\text { non-expected utility } \\
\text { (Sample No. }=80 \text { ) }\end{array}$ \\
\hline \multirow{2}{*}{ Time preference rates } & Mean & 0.0505 & 0.0814 \\
\hline & Standard error & 0.0069 & 0.0183 \\
\hline \multirow{2}{*}{$\begin{array}{l}\text { Risk aversion } \\
\text { coefficients }\end{array}$} & Mean & -0.0754 & 0.1969 \\
\hline & Standard error & 0.1086 & 0.1702 \\
\hline
\end{tabular}


Table 4: Time preference rates and risk aversion coefficients for smokers

\begin{tabular}{|c|c|c|c|}
\hline (a) & & $\begin{array}{c}\text { Smokers } \\
\text { Discounted utility } \\
\text { (Sample No.=164) }\end{array}$ & $\begin{array}{c}\text { Smokers } \\
\text { Non-discounted utility } \\
\text { (Sample No.=89) }\end{array}$ \\
\hline \multirow{2}{*}{ Time preference rates } & Mean & 0.0581 & 0.0903 \\
\hline & Standard error & 0.0092 & 0.0194 \\
\hline (b) & & $\begin{array}{c}\text { Smokers } \\
\text { Expected utility } \\
\text { (Sample No.=140) }\end{array}$ & $\begin{array}{c}\text { Smokers } \\
\text { Non-expected utility } \\
\text { (Sample No.=113) }\end{array}$ \\
\hline \multirow{2}{*}{$\begin{array}{l}\text { Risk aversion } \\
\text { coefficients }\end{array}$} & Mean & 0.0121 & 0.0891 \\
\hline & Standard error & 0.1409 & 0.1334 \\
\hline (c) & & $\begin{array}{c}\text { Smokers } \\
\text { Discounted \& } \\
\text { expected utility } \\
\text { (Sample No.=94) }\end{array}$ & $\begin{array}{c}\text { Smokers } \\
\text { Discounted \& } \\
\text { expected utility } \\
\text { (Sample No.=43) }\end{array}$ \\
\hline \multirow{2}{*}{ Time preference rates } & Mean & 0.0503 & 0.0877 \\
\hline & Standard error & 0.0103 & 0.0235 \\
\hline \multirow{2}{*}{$\begin{array}{l}\text { Risk aversion } \\
\text { coefficients }\end{array}$} & Mean & -0.0122 & 0.1299 \\
\hline & Standard error & 0.1680 & 0.2226 \\
\hline
\end{tabular}


Table 5: Time preference rates and risk aversion coefficients for non-smokers

\begin{tabular}{|c|c|c|c|}
\hline (a) & & $\begin{array}{c}\text { Non-smokers } \\
\text { Discounted utility } \\
\text { (Sample No.=169) }\end{array}$ & $\begin{array}{c}\text { Non-smokers } \\
\text { Non-discounted utility } \\
\text { (Sample No.=72) }\end{array}$ \\
\hline \multirow{2}{*}{ Time preference rates } & Mean & 0.0515 & 0.0567 \\
\hline & Standard error & 0.0077 & 0.0160 \\
\hline (b) & & $\begin{array}{c}\text { Non-smokers } \\
\text { Expected utility } \\
\text { (Sample No.=144) } \\
\end{array}$ & $\begin{array}{c}\text { Non-smokers } \\
\text { Non-expected utility } \\
\text { (Sample No.=97) }\end{array}$ \\
\hline \multirow{2}{*}{$\begin{array}{l}\text { Risk aversion } \\
\text { coefficients }\end{array}$} & Mean & -0.0121 & 0.1531 \\
\hline & Standard error & 0.1244 & 0.1464 \\
\hline (c) & & $\begin{array}{c}\text { Non-smokers } \\
\text { Discounted \& } \\
\text { expected utility } \\
\text { (Sample No.=109) } \\
\end{array}$ & $\begin{array}{c}\text { Non-smokers } \\
\text { Discounted \& } \\
\text { expected utility } \\
\text { (Sample No.=37) }\end{array}$ \\
\hline \multirow{2}{*}{ Time preference rates } & Mean & 0.0511 & 0.0621 \\
\hline & Standard error & 0.0095 & 0.0384 \\
\hline \multirow{2}{*}{$\begin{array}{l}\text { Risk aversion } \\
\text { coefficients }\end{array}$} & Mean & -0.1699 & 0.3547 \\
\hline & Standard error & 0.1402 & 0.3248 \\
\hline
\end{tabular}


Table 6: Time preference rates and risk aversion coefficients for pachinko

(a)

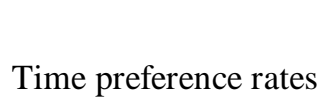

Pachinko

Discounted utility

(Sample No. $=78$ )

Mean

0.0745
0.0166

Pachinko

(b)

Expected utility

(Sample No.=66)

$0.0601 \quad 0.1021$

Mean
Pachinko

Non-discounted utility

(Sample No. $=40)$

\section{Risk aversion}

0.2117

0.2199

(c)

Standard error

Pachinko

Discounted \&

expected utility

(Sample No.=49)

Pachinko

Discounted \&

expected utility

(Sample No.=23)

\begin{tabular}{|c|c|c|c|}
\hline & & . & 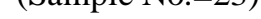 \\
\hline \multirow{2}{*}{ Time preference rates } & Mean & 0.0670 & 0.1345 \\
\hline & Standard error & 0.0199 & 0.0435 \\
\hline \multirow{2}{*}{$\begin{array}{l}\text { Risk aversion } \\
\text { coefficients }\end{array}$} & Mean & 0.0396 & 0.2928 \\
\hline & Standard error & 0.7800 & 0.3226 \\
\hline
\end{tabular}


Table 7: Time preference rates and risk aversion coefficients for non-pachinko

\begin{tabular}{|c|c|c|c|}
\hline (a) & & $\begin{array}{c}\text { Non-pachinko } \\
\text { Discounted utility } \\
\text { (Sample No.=255) }\end{array}$ & $\begin{array}{l}\text { Non-pachinko } \\
\text { Non-discounted utility } \\
\text { (Sample No.=121) }\end{array}$ \\
\hline \multirow{2}{*}{ Time preference rates } & Mean & 0.0508 & 0.0614 \\
\hline & Standard error & 0.0059 & 0.0128 \\
\hline (b) & & $\begin{array}{c}\text { Non-pachinko } \\
\text { Expected utility } \\
\text { (Sample No.=218) }\end{array}$ & $\begin{array}{c}\text { Non-pachinko } \\
\text { Non-expected utility } \\
\text { (Sample No.=158) }\end{array}$ \\
\hline \multirow{2}{*}{$\begin{array}{l}\text { Risk aversion } \\
\text { coefficients }\end{array}$} & Mean & 0.0010 & 0.1220 \\
\hline & Standard error & 0.1026 & 0.1090 \\
\hline (c) & & $\begin{array}{c}\text { Non-pachinko } \\
\text { Discounted \& } \\
\text { expected utility } \\
\text { (Sample No.=154) }\end{array}$ & $\begin{array}{c}\text { Non-pachinko } \\
\text { Discounted \& } \\
\text { expected utility } \\
\text { (Sample No.=57) }\end{array}$ \\
\hline \multirow{2}{*}{ Time preference rates } & Mean & 0.0475 & 0.0622 \\
\hline & Standard error & 0.0072 & 0.0183 \\
\hline \multirow{2}{*}{$\begin{array}{l}\text { Risk aversion } \\
\text { coefficients }\end{array}$} & Mean & -0.1264 & 0.1661 \\
\hline & Standard error & 0.1243 & 0.1936 \\
\hline
\end{tabular}


Figure 2: Socio-economic and economic-psychological models

External and Internal Influences:

1) Personal Capital

2) Consumption Capital

3) Social Capital

4) Society and Community

5) Current Life Situation

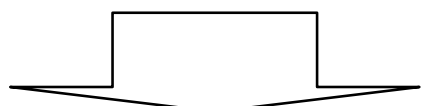

Degree of Imbalance

Represented by Economic-Psychological Parameters:

1) Time Preference

2) Risk preference

3) Time Inconsistency

4) Risk Inconsistency

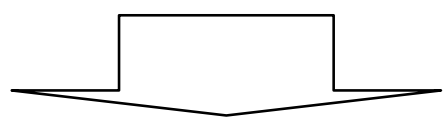

Bias in Perception of Benefits and Costs

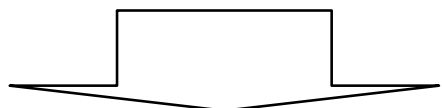

Addiction or Not 